\title{
A Prospective analysis on Minimization of Mechanical Friction of Fuel Engine Using Chemical Reagents
}

\author{
Shaheen Shah*, Nasirul Islam, Shimul Hossain, Abu Hena, Nasimul Jamil, Sumon Chowdhury and Anas Al-Hossain
}

Department of Petroleum and Mining Engineering, Jessore University of Science and Technology, Bangladesh

\begin{abstract}
Chemical reagents such as Lithium base grease, Calcium base grease, Aluminum base grease which are reduced the mechanical friction and increase the performance of machines with adding various additives molybdenum disulphide $\left(\mathrm{MoS}_{2}\right)$, Graphite, Boron Nitrite. Dropping point is an indicator of heat resistance of the grease. The dropping point indicates the upper temperature limit at which grease retains its structure. If, failure the grease against high temperature then occurs friction and increase load. When load is increase then the fuel engine does not give the satisfy output. The paper estimated the dropping point of those grease. A.S.T.M standard D-566 used for estimated dropping of the greases. The dropping point of Lithium base grease, Calcium base grease, Aluminum base grease are estimated $195^{\circ} \mathrm{C}, 95^{\circ} \mathrm{C}$, and $110^{\circ} \mathrm{C}$ respectively. The dropping point of mixed base grease i.e., Calcium 50\% + Lithium 50\%, Lithium 50\% + Aluminum $50 \%$ and Calcium $50 \%+$ Aluminum $50 \%$ are $140^{\circ} \mathrm{C}, 158^{\circ} \mathrm{C}$ and $152^{\circ} \mathrm{C}$ respectively. The dropping of mixed base grease is higher than the individuals of the greases. The use of the calcium base grease also act is a water and repellant and corrosion protective. This paper represents that Aluminum $50 \%$ + Calcium $50 \%$ mixed base grease is showing the best performance against high temperature with protects the corrosion.
\end{abstract}

Keywords: Grease; Dropping point; Friction; Lubrication; Fuel engine

\section{Introduction}

Chemical reagent such as grease is a solid or semi-solid combination of petroleum products and soap or mixtures of soaps with or without fillers, suitable for certain type of lubrication. Grease is a lubricant of higher initial viscosity than oil, consisting originally of a Calcium, Lithium, soap jelly emulsified with oil [1-5]. The manufacturing of grease involves dispersion of a thickener in the oil. The thickener or jelling agent in over $90 \%$ of grease is a metallic soap. The usual method by which a metallic soap thickener is formed (fat + metal hydroxide). This reaction is carried out by cooking the fatty material and alkali with normally some oil in order to get the soap well dispersed and also to make it softer and easier to stir [6,7].

The Lithium base grease is high water resistance and high temperature properties. The use of Lithium base grease is to increase of mechanical stability. But the disadvantage is pump ability at low temperatures. It can present a difficulty in centralized lubrication systems at temperatures below $-10^{\circ} \mathrm{C}$ [8-10]. The Calcium base grease is high operational temperature and it is water resistance with mechanically stable. Aluminum base grease is excellent oxidation and water resistance but tends to have poor mechanical stability [11].

Friction and lubrication play a vital role in energy conservation. Low friction and suitable lubrication are related with engine integrity and good performance. The lubricant influences the lubrication regimes of the lubricated parts. Additives maintain temperature sensitivity; reduce solid to solid friction [12-14]. Friction is the force that opposes the motion of an object. Another friction is the resistance to the sliding of one solid body over or along another, as solid bodies are ordinarily understood in the macroscopic world [15].

When the temperature is high in the part of engine then it is so necessary to maintenance the lubricant system otherwise, create friction and failure the satisfy output due to increase high load. Corrosion is high if friction is increase so, it is most important to use of proper lubricant in the part of engine [16-18]. Where, Calcium base grease is used to the point of wet condition in pump area. Aluminum base grease is used plain bearing; low shear point and lithium base grease is used long supply area. To use of individual greases in the individual's area is so complexity and high cost. Again, there is no need to add corrosion inhibitor to Calcium base grease [19] and Calcium and Aluminum mixed base grease is show high dropping point which is indicates best performance against high temperature in the fuel engine [20-22].

\section{Materials and Methods}

The materials used in this test (Dropping point measurement) are lithium base grease, calcium base grease and aluminum base grease. All of those materials are collected in the local market. Compositions of materials are lithium base grease (Metal of Lithium + Lithium's Fatty acid + Base oil), Calcium base grease (Metal of Calcium + Calcium's Fatty acid + Base oil) and aluminum base grease (Metal of Aluminum + Aluminums Fatty acid + Base oil) [23-25]. All are tested on the Institute of Fuel Research and Development in the Bangladesh Council of Scientific and Industrial Research (B.C.S.I.R).

Place the cork on one of the thermometers so that the tip of the thermometer build will be about $1 / 8$ " above the bottom of the grease cup when the apparatus is assembled the other cork is placed equidistant between the lower end of upper cork and the grease cup as per the Figure 1. This cork will have to be worked cut to fit inside the

"Corresponding author: Md. Shaheen Shah, Department of Petroleum and Mining Engineering, Jessore University of Science and Technology, Bangladesh, Tel: +88-0171-0785055; E-mail: shaheenshah_just@yahoo.com

Received September 04, 2017; Accepted September 30, 2017; Published October 05, 2017

Citation: Shah S, Islam N, Hossain S, Hena A, Jamil N, et al. (2017) A Prospective analysis on Minimization of Mechanical Friction of Fuel Engine Using Chemical Reagents. J Pet Environ Biotechnol 8: 341. doi: 10.4172/2157-7463.1000341

Copyright: ( 2017 Shah S, et al. This is an open-access article distributed under the terms of the Creative Commons Attribution License, which permits unrestricted use, distribution, and reproduction in any medium, provided the original author and source are credited. 
Citation: Shah S, Islam N, Hossain S, Hena A, Jamil N, et al. (2017) A Prospective analysis on Minimization of Mechanical Friction of Fuel Engine Using Chemical Reagents. J Pet Environ Biotechnol 8: 341. doi: 10.4172/2157-7463.1000341

test tube. Suspend the other thermometer into the oil bath so that its bulb will about the same level of the test tube [26].

Fill the grease cup with a sample of grease and gently press the grease into the cup until a small amount is extruded at the small opening. Using metal road cut a wedge of grease from the cup by revolving the cup against the rod and simultaneously pushing the upward. A smooth film of grease shall remain in the cup.

Assemble the apparatus, start the stirrer and heat at a rate of $8-12^{\circ} \mathrm{F}$ per minute until the bath reaches a temperature approximately $30^{\circ} \mathrm{F}$ below the expected dropping point. Reduce the rate of heating sop that the temperature in the best tube will be within $4^{\circ} \mathrm{F}$ or less of the bath temperature. As the temperature increases the grease will slowly protrude through the orifice of the cup. The temperature at which a drop of grease falls to the bottom of the cup is the dropping point. If the drop has a tailing thread, the test is continued until it breaks completely $[27,28]$.

The dropping point calculated as following equation,

$$
D P=O D P+\left[\frac{B T-O D P}{3}\right]
$$

Where,

$\mathrm{DP}=$ Dropping point.

ODP $=$ Thermometer reading when first drop reaches the bottom of the test tube, and

$\mathrm{BT}=$ Block temperature when the drop fall.

\section{Results and Discussion}

The study estimated the dropping point of grease both as mixed and individually. The individual grease is A (calcium) base, B (Lithium) base, $\mathrm{C}$ (Aluminum) base which are tested in B.C.S.I.R. The dropping

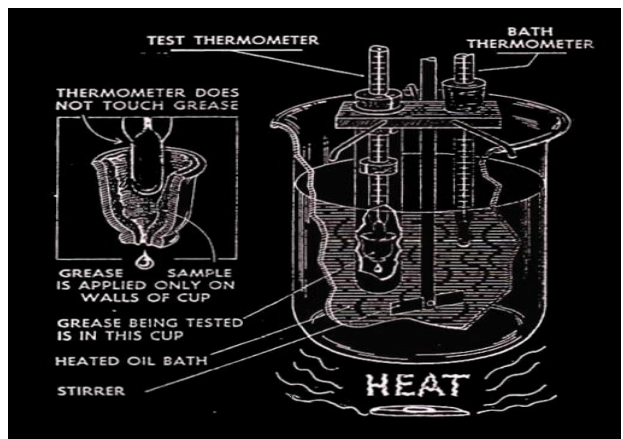

Figure 1: Test procedure dropping point grease [36].

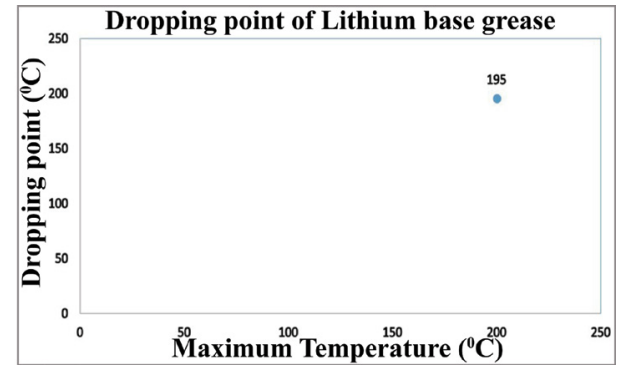

Figure 2: Dropping point of lithium base grease.

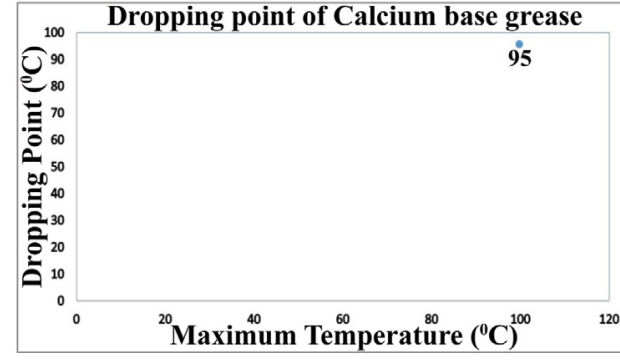

Figure 3: Dropping point calcium base grease.

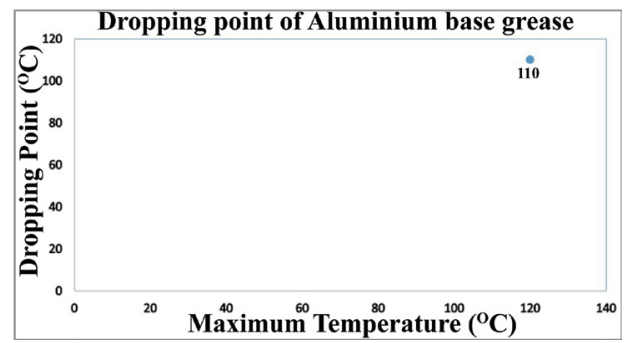

Figure 4: Dropping point aluminum base grease.

\begin{tabular}{|c|c|}
\hline Grease & Dropping Point \\
\hline A (Calcium) & $95^{\circ} \mathrm{C}$ \\
\hline B (Lithium) & $195^{\circ} \mathrm{C}$ \\
\hline C (Aluminum) & $110^{\circ} \mathrm{C}$ \\
\hline
\end{tabular}

Table 1: Dropping point of individuals grease.

\begin{tabular}{|c|c|}
\hline Grease & Dropping Point \\
\hline $\mathrm{A}+\mathrm{B}($ Calcium $50 \%+$ Lithium $50 \%)$ & $140^{\circ} \mathrm{C}$ \\
\hline $\mathrm{A}+\mathrm{C}($ Calcium $50 \%+$ Aluminum $50 \%$ & $158^{\circ} \mathrm{C}$ \\
\hline $\mathrm{B}+\mathrm{C}($ Lithium $50 \%+$ Aluminum $50 \%)$ & $152^{\circ} \mathrm{C}$ \\
\hline
\end{tabular}

Table 2: Dropping point of mixed grease.

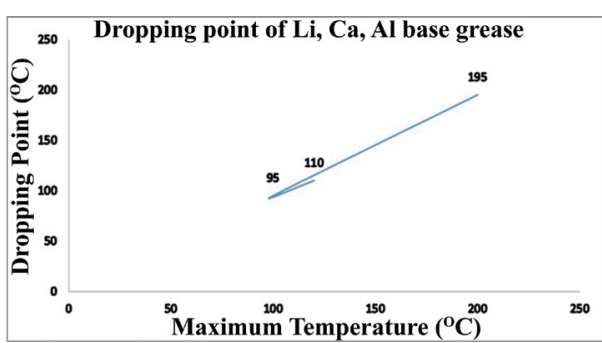

Figure 5: Dropping points of $\mathrm{Li}, \mathrm{Ca}, \mathrm{Al}$ base greases with scatter line diagram.

point of A (calcium), B (Lithium), C (Aluminum) are estimated $95^{\circ} \mathrm{C}$, $195^{\circ} \mathrm{C}$ and $110^{\circ} \mathrm{C}$ respectively that shows in Figures 2-4 and Tables 1 and 2.

The lithium grease trend to be liquid at the actual point of $195^{\circ} \mathrm{C}$ when the temperature at the point of $200^{\circ} \mathrm{C}$ or above. The dropping point of Lithium base grease shows by scatter diagram in Figure 2 and Table 1 . The Lithium base grease dropping point is high $\left(195^{\circ} \mathrm{C}\right)$ but have to some demerits that is metal effects on the mechanical parch.

The calcium grease trend to be liquid at the actual point of $95^{\circ} \mathrm{C}$ that show in Figure 3. This dropping point consider as moderately high The maximum temperature trend to be liquid at $120^{\circ} \mathrm{C}$ for aluminum based grease. The actual dropping point at $110^{\circ} \mathrm{C}$ (high) that is shown in Figure 4. At that point grease fall-down. 
Citation: Shah S, Islam N, Hossain S, Hena A, Jamil N, et al. (2017) A Prospective analysis on Minimization of Mechanical Friction of Fuel Engine Using Chemical Reagents. J Pet Environ Biotechnol 8: 341. doi: 10.4172/2157-7463.1000341

The ascending and descending curve of scatter line diagram is shown in Figure 5 for $\mathrm{Li}, \mathrm{Ca}$ and $\mathrm{Al}$ base greases. The maximum temperature is applying at $200^{\circ} \mathrm{C}$. Dropping points of $\mathrm{Li}, \mathrm{Ca}, \mathrm{Al}$ base greases are represented by scatter diagram shows in Figure 6 and Table 2. To show the tested results and curve analysis of the individuals greases $\mathrm{Li}$ is high and it has to metal effects. Other none they are have moderately high and have to corrosive solution.

Mixed grease are A + B (Calcium 50\% + Lithium 50\%) base grease, $\mathrm{A}+\mathrm{C}$ (Calcium $50 \%+$ Aluminum $50 \%$ ) base grease and B $+\mathrm{C}$ (Lithium $50 \%+$ Aluminum 50\%) base grease. The dropping point of $\mathrm{AB}, \mathrm{AC}$, $\mathrm{BC}$ is $140^{\circ} \mathrm{C}, 150^{\circ} \mathrm{C}$ and $152^{\circ} \mathrm{C}$ respectively that shows in Figure 7 . The bearable maximum temperature grease is $158^{\circ} \mathrm{C}$ of the $\mathrm{AC}$ (Calcium and Aluminum base greases).

It is clear that the Lithium base grease is shown the maximum

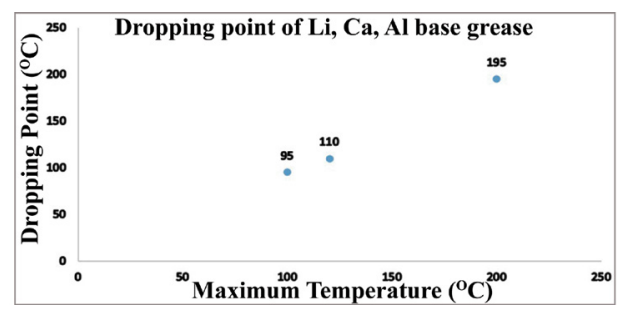

Figure 6: Dropping points of $\mathrm{Li}, \mathrm{Ca}, \mathrm{Al}$ base greases with scatter diagram.

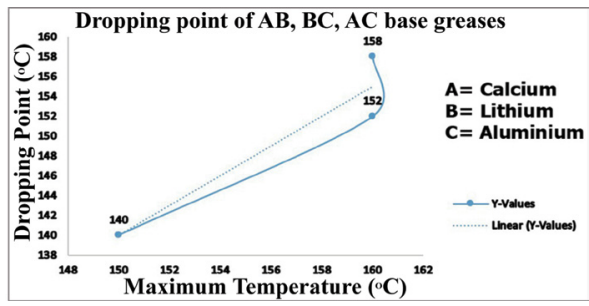

Figure 7: Dropping points of mixed greases. $A B\left(140^{\circ} \mathrm{C}\right), B C\left(152^{\circ} \mathrm{C}\right), A C$ $\left(158^{\circ} \mathrm{C}\right)$.

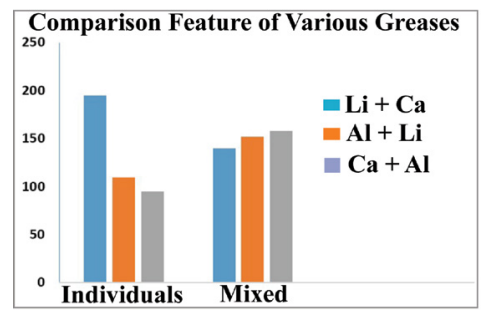

Figure 8: View of the dropping points of two group greases.

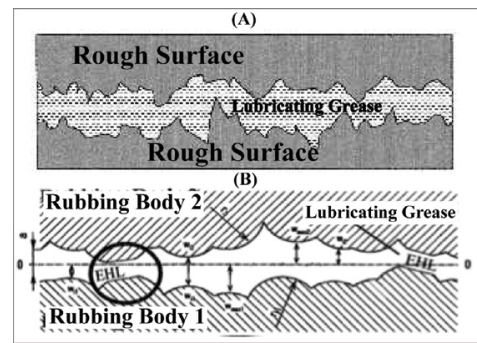

Figure 9: (A) Grease lubricated contact with two rough surfaces; (B) Modeled mixed friction contact of a grease lubricated gap [22]

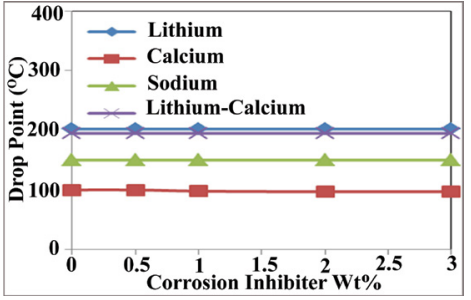

Figure 10: Effect of corrosion inhibitor additive on drop point test [27]

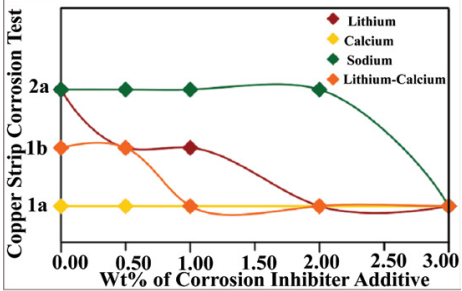

Figure 11: Effect of corrosion inhibitor additive on copper strip corrosion test [27]

dropping point temperature $\left(195^{\circ} \mathrm{C}\right)$ of the individuals grease group and Calcium + Aluminum base grease is show maximum dropping point temperature $\left(158^{\circ} \mathrm{C}\right)$ of the mixed grease group in Figure 8.

Dropping point is an indicator of the heat resistance of grease. As grease temperature raises penetration increase until the grease liquefies and the desired consistency is lost [29]. Dropping point the temperature which grease becomes fluid enough to drip. The dropping point indicates the upper temperature limit which a grease retains structure [30]. There are hundreds of moving parts of engine and others so, every one of these things Russ against something else as it moves making noise, losing energy to friction and gradually wearing out, wood ford, Chris lubricants [31,32]. Grease lubricated contract are often working in mixed friction. That means liquid friction (grease film) and solid friction (asperity deformation) have to be considered [33-35] that shows in Figure 9.

A common way to reduce friction is by using a lubricant, such as grease which is placed between the two surfaces, often dramatically lessening the coefficient of friction. Lubricants to overcome friction need not always be thin. Lubricated friction is a case of fluid friction where a fluid separates two solid surfaces. When lubrication breaks down, metal or other components can rub destructively over each other [36,37].

The drop point temperature remained constant despite the increase in additive in Lithium grease but except for Calcium grease which shows in Figure 10. Again, Calcium base grease no needs additives for corrosion protect due to the curve (Calcium) shows that straight line to the Corrosion Inhibiter additive shows in Figure 11. In the fuel engine is occur the spark as a result need to high resistance grease withstand against high temperature. If, failure the grease against high temperature then occurs friction and increase load. On the other hand, seen that calcium base grease is a water repellant and corrosion protective that shown in Figures 10 and 11 [38,39].

\section{Conclusion}

A modern internal combustion engine is comprised of dozens of moving components. Without appropriate oiling, these parts run against each other with incredible speed, creating friction which then 
Citation: Shah S, Islam N, Hossain S, Hena A, Jamil N, et al. (2017) A Prospective analysis on Minimization of Mechanical Friction of Fuel Engine Using Chemical Reagents. J Pet Environ Biotechnol 8: 341. doi: 10.4172/2157-7463.1000341

leads to heat. This heat can wear the mechanical parts of an engine and lead to bad performance under the hood. Worn parts due to friction cause have with gas mileage and emissions since the engine is pushed to work harder. Wear on the engine's vehicle is a primary known cause of less efficient burning of fuel. It is clear that AC (Aluminum+ Calcium) base grease show the maximum dropping point $\left(158^{\circ} \mathrm{C}\right)$ against temperature. Also, to see from the mixed base grease comparison $\mathrm{AC}$ (Aluminum+ Calcium) show maximum dropping point temperature $\left(158^{\circ} \mathrm{C}\right)$. Where the dropping point is useful to assist in identifying the grease as type and for establishing and maintaining bench marks with quality control and service performance.

Dropping point is a qualitative indicator of the heat resistance of grease on application semi-solid lubricant is essential on the other hand corrosion problem is most significance in the fuel engine component. If to use of Calcium base grease it is not importance to use of the additives due to Calcium base grease is auto water repellant with fiber length. So, if it is possible to use of the mixed grease (Calcium + Aluminium) of the fuel engine part, it gives two supports the one is sustainable against to the high temperature and two is protect the corrosion problem.

\section{References}

1. Canter DN (2013) Grease additives: Important contributors not to be overlooked Tribology \& Lubrication Technology.

2. Hobson GD (1975) Modern petroleum technology. (4th edn), Applied Science Publishers, Barking, UK.

3. Lugt PM (2009) A review on grease lubrication in rolling bearings. Journal of Tribology Transactions 52: 470-480.

4. Lugt PM (2012) Grease lubrication in rolling bearings. SKF, John Wiley \& Sons NY, USA.

5. Perry RH, Green DW (1997) Perry's chemical engineers' handbook. (7th edn), Published by McGraw-Hill Professional Hardcover, USA.

6. Boner CJ (1954) Manufacture and application of lubricating greases. (1st edn), Hardcover, Reinhold Publishing, NY, USA

7. Speight JG (2015) Handbook of petroleum product analysis, Chapter 13, Grease. (2nd edn). Wiley \& Sons, Inc, NY, USA

8. Hasting JR (1981) Lithium and lithium complex greases for use in the steel industry. Lubrication Engineering 37: 91-94.

9. Izcus AG (1980) The effects of lead compounds upon the dropping points of lithium lubricating grease. NLGI Spokesman 44: 280-290.

10. White Paper (2004) The chemistry and physics of grease -The advantages of grease. Lubrisense ${ }^{\mathrm{TM}}$.

11. Cyriac F, Lugt PM, Bosman R (2016) Impact of water on the rheology of lubricating greases. Journal of Tribology Transactions 59: 679-689.

12. Briant J, Denis J (1998) Lubricant properties, analysis and testing. Technical edition, Technip 1: 2

13. Brithwaite ER (1967) Lubrication and lubricants. Elsevier Scientific Publishing Company, Amsterdam.

14. Wong VW, Tung SC (2016) Overview of automotive engine friction and reduction trends-Effects of surface, material, and lubricant-additive technologies. Friction 4: 1-28.

15. Escobar J (2007) Principles of lubrication. Aircraft Maintenance Technology, Aviation Pros 1: 2
16. Guy T (2013) Heat and friction: Primary enemies of car engines. Fuel \& Friction, Boost Performance Products.

17. Sharma SK, Vasudevan P, Tewari US (1983) High temperature lubricants-oils and greases. Tribology International 16: 213-219.

18. Sliney HE (1982) Solid lubricant materials for high temperatures-A review. Tribology International.

19. Mohammed MAR (2013) Effect of additives on the properties of different types of greases. Iraqi Journal of Chemical and Petroleum Engineering 14: 11-21.

20. Couronné I, Vergne P, Mazuyer D, Dinh NT, Girodin D (2003) Effects of grease composition and structure on film thickness in rolling contact. Journal of Tribology Transactions 46: 31-36.

21. Couronné I, Vergne P, Mazuyer D, Dinh NT, Girodin D (2003) Nature and properties of the lubricating phase in grease lubricated contact. Journal of Tribology Transactions 46: 37-43.

22. Lugt PM, Velicjov S, Tripp JH (2009) On the chaotic behavior of grease lubrication in rolling bearings. Journal of Tribology Transactions 52: 581-590.

23. Debenedetto M (1997) Lubricant reference manual. Technical Chesterton products. Middlesex Industrial Park, (A).W. Chesterton Co. USA.

24. Polishuk A (1998) A brief history of lubricating greases. Grease Technology, Lima, PA, USA.

25. Kaperick J (2010) Grease - The other lubricant, STLE Philadelphia Section presentation.

26. Designation: D 566 - 02, Designation: 132/96. Standard test method fo dropping point of lubricating grease, 2002. An American National Standard British Standard 2877, USA.

27. Hobson GD, Pohl W (1973) Modern petroleum technology. Wiley Publications, NY, USA.

28. Scott R, Fitch J, Leugner L (2012) The practical handbook of machinery lubrication - (4th edn). Noria Corporation.

29. Salomonsson L, Stang G, Zhmud B (2007) Oil/thickener interactions and rheology of lubricating greases. Journal of Tribology Transactions 50: 302-309.

30. Bonor CJ (1994) Manufacture and application of lubricating greases. National Lubricating Grease Institute, USA.

31. Hunter M, Rizvi S, Baker R (2001) Ashless rust inhibitors for greases. NLG Spokesman 65: 24-32.

32. Mang T, Dresel W (2007) Lubricants and lubrication. (2nd edn). John Wiley \& Sons, Inc, NY, USA.

33. Cen H, Lugt PM, Espejel GM (2014) On the film thickness of grease-lubricated contacts at low speeds. Journal of Tribology Transactions 57: 668-678.

34. Couronné I, Vergne P, Mazuyer D, Dinh NT, Girodin D (2008) Effects of grease composition and structure on film thickness in rolling contact. Journal of Tribology Transactions 46: 31-36.

35. Kuhn E (2013) Friction and wear of a grease lubricated contact-An energetic approach. Tribology- Fundamentals and Advancements Chapter 9. InTech.

36. Singh T (2008) Tribochemistry and EP activity assessment of Mo-S complexes in lithium-base greases. Advances in Tribology.

37. Zheng EC, Qian XL (1989) Tribological properties and lubrication mechanism of molybdenum dialkyl-dithiocarbamate and calcium compounds in greases. Wear 130: 233-247.

38. Fitch J, Troyer D (2010) Oil analysis basics. (2nd edn) paper back, Noria Corporation Publication, USA.

39. Totten GE, Tung S (2012) Automotive lubricants and testing. ASTM Internationa Publication, USA. 